axis and are not independent cylinders. He states that no case is known to him in which the idiomorphic forms of the crystals are segments of spherical shells which have crystallised out of a liquid except in the ternary alloys referred to. The reason why idiomorphic shell crystals develop under such conditions and the laws which govern their formation await further research. Meantime, Prof. Bragg, to whom some of the separated crystals have been sent, has kindly promised to study them.

H. C. H. C.

\section{FORECASTING FROSTS.}

I $\mathrm{N}$ most countries during the spring, and to a lesser extent in the autumn, there are periods in which Leaving out of the question spells of cold weather, the prediction of which is the concern of a Meteorological Service, there remains the possibility of local frosts in isolated districts, occurring on clear, windless nights and lasting for a portion of the night and early morning. These frosts are capable of doing great damage to fruit-trees, etc., and the possibility of forecasting them in time for the fruit-growers to take precautions is of interest and importance.

It has long been recognised that local cooling of the soil can be largely prevented by a smoke pall produced by the burning of damp materials such as straw. Boussingault ("Economie Rurale," Paris, I844) discusses this, and records an observation on the point by Pliny. In America definite systems of frost prediction have been in operation for some years, and practical methods have been evolved by which the grower can economically combat the danger to his crops. A study of these preventive measures is instructive in showing that several causes are concerned in producing a frost. The methods are varied. Leaving out those which attempt to delay the flowering-time until the danger period is past, they fall into four main classes:- (I) Increasing the water-content of the area (spraying or flooding); (2) "smudge" burning (damp smoke from wet straw, etc.); (3) temporary roofing; and (4) dry heating. The last method supplies additional heat mainly; the other three are largely indirect, and aim at reducing the rate of temperature fall either by increasing the heat capacity of the soil by the added water or by restricting the radiation from the soil.

$U_{p}$ to the present no complete correlation has been made of frost in any particular locality and its causes. For this purpose an examination by statistical methods of a series of continuous observations (of the automatic recording type) of meteorological factors is needed. The published papers deal usually with cne factor, such as dew-point or air temperature, and the number of daily observations made is small. This is, no doubt, due to the necessity of keeping the cost of apparatus and working as fow as possible for the sake of the growers. However, a general idea of the factors concerned can be obtained from a broad survey of the various papers.

The effect of an overcast sky on air temperatures near the ground has been studied by Hellman (Preuss. Akad. Wiss., Berlin, 38, 1918, p. 806), who on clear nights found an exponential decrease of temperature with height, the average difference from ground-level to a height of $50 \mathrm{~cm}$. being $3.7^{\circ} \mathrm{C}$. An increase of cloudiness by $\mathrm{I}^{\circ}$ of scale $(\mathrm{o}=$ clear, Io=overcast) diminished this difference by at least $\frac{1}{3} .0$ C. There was no temperature gradient when the sky was overcast, while windy and rainy weather resulted in a slight reversal of the gradient. Schubert (Met. Ztsch., 32, 1915, p. 343) considers that during the last half of the night the fall of temperature is NO. $26 \mathrm{I} 8$, VOL. IO4] relatively greater with dry than with moist air, owing to the formation of dew, and frost from the latter resulting in latent heat being set free by the condensation. The presence of water-vapour in the atmosphere also retards the radiation cooling of the soil.

J. Warren Smith (U.S. Monthly Weather Review, 42 , 1914, p. $573 ; 45$, 1917 , p. 402) has examined the accuracy of various methods of temperature prediction. 'The first, and simplest, is to subtract from the maximum temperature of the day the known average fall in temperature on clear, still afternoons and evenings for the appropriate period of the year. This temperature range varies in different months, but is remarkably uniform under similar topographical conditions and at similar seasons of the year. It has been used by Church (Nevada Station Report, I915, p. 46).

The second method is due to Smith, and involves two temperature readings daily. Smith discovered that the daily temperature curves showed marked similarity in periods of caim, clear weather when a high-pressure system was centred over the district and conditions were favourable for strong insolation during the day and free radiation at night. For these curves the half-way point in the temperature fall from the maximum of one day to the minimum of the next morning (the "median") occurred at very nearly the same time. Hence a forecast of the probable minimum can be made by subtracting from the maximum the temperature shown at the time previously ascertained to be that of the median. and then subtracting this difference in turn from the observed median temperature. The values thus obtained agreed much more closely with the observed minima than those given by the original dew-point method, which is mentioned immediately below.

The third method, as developed by Smith, is an elaboration of the dew-point determination. This, as used by Hazen (Minn. Expt. Sta. Bull. I2, 189o), and by O'Gara (U.S. Farmers' Bull. No. 401, I9I.), consists simply in determining the dew-point in the early evening (6-Io p.m.), and assumes the dew-point temperature will be the probable minimum temperature reached. Smith found that the prediction could be made much more accurately if the relative humidity of the atmosphere was also determined, and he used the correlation method to show that with high relative humidity the minimum temperature falls below the determined Gew-point, while with low relative humidity the reverse is true. A satisfactory equation expressing this relation was obtained,

$$
Y=18314-0.39 R
$$

where $R=$ relative humidity in the evening, and $Y$ is departure of minimum temperature of the following morning from evening dew-point. A determination of $R$ gives the value of $Y$, which added to (or subtracted from) the dew-point gives the probable minimum temperature to be expected. The numerical terms in the equation differ for different localities.

Recently T. B. Franklin (Proc. Roy. Soc. Edin., 39 , I9r9, p. r2o) has published some observations on the cooling of the soil at night, with special reference to late spring frosts, and has arrived at a number of important conclusions, which will help considerably in developing methods for forecasting the minimum surface-soil temperature in this country. As a result of observations of temperatures in the air, on the soil, and at a depth of 4 in., Franklin concludes that a prediction of frost depends on assessing the value of:-(I) Average relative humidity during the night; (2) the temperature of a given depth (4 in.) at the time of surface minimum temperature; (3) the conductivity of the layer between the assigned depth 
and the surface; and (4) the difference between the surface-soil minimum and that of the air above it These determinations are necessary because:-(i) The radiation from the soil on calm, clear nights is a function of the relative humidity (A. Angström, Smithsonian Misc. Coll., $6_{5}$ No. 3); (ii) the radiation from the soil can be accounted for in balancing the upward conduction and the latent heat of freezing, the residue only cooling the soil; and (iii) the temperature of the surface soil rapidly falls sufficiently below the temperature of the 4-in. depth to make the conduction from this depth balance the radiation; after this the surface temperature falls no faster than that of the 4-in. depth.

Franklin has also noted rapid changes in underground temperature (6-in. depth) after heavy rain. This he attributes to the receding water drawing hot or cold air into the soil, but it is scarcely possible that the volume of air thus drawn in could supply or abstract sufficient heat to account for the observed differences. These latter are in the direction which would be expected from the time of the day when the readings were taken; and while the re-aëration of the soil may have slightly increased the temperature changes, it is unlikely that it had a predominating influence.

B. A. KEEN.

\section{LUBRICATION AND LUBRICANTS}

THE meeting of the Physical Society held on November 28 was devoted to a discussion on the subject of lubrication, suggested by a paper on "Oili. ness and Lubrication" by Mr. R. M. Deeley, sent by the Committee on Lubrication. Other contributors included Dr. Stanton, Principal Skinner, Messrs. W. B. Hardy, Dorman, Southcombe, Martin, Archbutt, Edser, and Dr. H. S. Allen.

In the consideration of lubrication problems a clear distinction must be made between two prevailing conditions, viz.: (I) Those in which the solid surfaces are completely separated by a film of oil, as occurs in the lubrication of cylindrical journals and their bearings working under moderate pressures, revolving at high speed, and supplied with abundance of oil; and (2) those in which, owing to the shape or condition of the surfaces, the kind of motion, high bearing pressure, low speed, or an inadequate supply of oil, the oil-film cannot form completely, or becomes broken, and the solid surfaces come into contact. In (I) the friction is entirely due to the viscosity of the oil, as proved by Beauchamp Tower and Osborne Reynolds. Engineers have Reynolds's theory to guide them in the design of bearings so as to secure fluid friction, and it is possible by determining the viscosity and chemical characteristics of an oil to form a sound opinion as to its suitability to meet the required conditions. In (2) the circumstances are quite different. Lubricating value is then found to depend upon some property which is quite distinct from viscosity, and has been called "oiliness."

In opening the discussion Dr. Stanton referred to experiments recently made at the National Physical Laboratory for the Lubrication Committee with the lanchester worm-gear testing machine, in which working pressures of several tons per square inch are developed, showing that in the case of all the mineral oils tested the lubrication at a certain temperature suddenly became imperfect, the friction irregular, and the efficiency of the gear fell off. With fixed oils no such "breaking-down" point was observed under the conditions of the tests, and it was found that by adding quite a small percentage of fatty oil to a mineral oil the breaking-down point, No. 26 I 8 , VOL. IO 4$]$ though not obliterated, occurred at a higher temperature.

Mr. Deeley described and exhibited a small handdriven machine which he had invented for the purpose of measuring the oiliness of lubricants under conditions of metallic contact. Three flat-ended metal studs, each $5 / 32^{\prime \prime}$ in diameter, secured concentrically as feet to a metal disc, rested upon another metal disc which could be slowly rotated. The upper disc could be weighted as desired, and actuated a spindle to which a spiral spring and a recording finger were attached. The lower disc, when rotated, carried the studs and upper disc with it by friction until the stress in the spring caused the surfaces to slip, when the pointer gave the frictional resistance, oscillations being damped by gearing the spring and pointer to a train of wheels. Experiments made with this machine showed that the static friction depended upon the nature of the metal surfaces in contact as well as upon the oil, and the fatty oils which in practice are found to be the best lubricants gave lower static coefficients than the mineral oils. Mr. Deeley's view is that the oil, or some constituent of it, enters into physico-chemical union with the comparatively rigid metallic surface, forming a composite film having the yielding nature of velvet-pile, and that the best lubricants are those which produce the most easily sheared contact films.

Dr. Allen directed attention to the important work of Irving Langmuir on surface films, and suggested that the property of "oiliness" depends upon the chemical forces called into play between the active part of the oil molecule and the solid surface of the bearing, and not only on the nature of the lubricant, but also on that of the solid surfaces with which the liquid is brought into contact.

Mr. W. B. Hardy referred to the work carried on by his son and himself, and discussed by them in the Philosophical Magazine of July last. In the apparatus they used there was only one point of contact between the solid surfaces, which consisted at first of a curved watch-glass on a flat glass plate, and latterly of similarly shaped surfaces of bismuth. The force measured was that necessary to cause the curved surface to slide over the plate when lubricated by the films formed by individual chemical substances representative of various groups of chemical compounds. The authors concluded that the true function of a lubricant was to reduce the energy of the surface, and thereby to reduce the capacity for cohesion and the resistance to slip when two composite surfaces are applied one to the other. This, in the opinion of the present writer, is the conclusion to which all recent work leads, and the problem before the chemist is to determine in what manner the molecular structure of the chemical compounds in lubricants determines their "oiliness."

The practical side of the problem cannot, however, be neglected, and it is necessary to experiment with commercial lubricants acting between such dissimilar metal surfaces as are used in the construction of machines, in order to obtain the information which engineers require to guide them in the lubrication of machinery. Mr. Southcombe's observation that the interfacial tension between oil and water and oil and mercury is much higher with mineral oils than with fatty oils, and that the addition of a very little free oleic acid to a mineral oil greatly lowers the surface tension, is of great importance. It appears that by adding I per cent. of free fatty acid to a mineral oil the lubricating power is increased as much as by adding a verv much larger percentage of fatty oil. The emulsifying properties can also be materially modified by the addition of fatty acids. 